\title{
Landscape features and weather influence nest survival of a ground-nesting bird of conservation concern, the greater sage-grouse, in human- altered environments
}

Stephen L Webb ${ }^{1 *}$, Chad V Olson ${ }^{1}$, Matthew R Dzialak ${ }^{1}$, Seth M Harju ${ }^{1}$, Jeffrey B Winstead ${ }^{1}$ and Dusty Lockman ${ }^{2}$

\begin{abstract}
Introduction: Ground-nesting birds experience high levels of nest predation. However, birds can make selection decisions related to nest site location and characteristics that may result in physical, visual, and olfactory impediments to predators.

Methods: We studied daily survival rate [DSR] of greater sage-grouse (Centrocercus urophasianus) from 2008 to 2010 in an area in Wyoming experiencing large-scale alterations to the landscape. We used generalized linear mixed models to model fixed and random effects, and a correlation within nesting attempts, individual birds, and years.

Results: Predation of the nest was the most common source of nest failure (84.7\%) followed by direct predation of the female (13.6\%). Generally, landscape variables at the nest site $(\leq 30 \mathrm{~m})$ were more influential on DSR of nests than features at larger spatial scales. Percentage of shrub canopy cover at the nest site (15-m scale) and distances to natural gas wells and mesic areas had a positive relationship with DSR of nests, whereas distance to roads had a negative relationship with DSR of nests. When added to the vegetation model, maximum wind speed on the day of nest failure and a 1-day lag in precipitation (i.e., precipitation the day before failure) improved model fit whereby both variables negatively influenced DSR of nests.

Conclusions: Nest site characteristics that reduce visibility (i.e., shrub canopy cover) have the potential to reduce depredation, whereas anthropogenic (i.e., distance to wells) and mesic landscape features appear to facilitate depredation. Last, predators may be more efficient at locating nests under certain weather conditions (i.e., high winds and moisture).
\end{abstract}

Keywords: behavior, Centrocercus urophasianus, conservation, depredation, generalized linear mixed models, greater sage-grouse, human development, management, nest survival, weather

\section{Introduction}

Predators can influence and regulate prey populations (Crooks and Soulé 1999). A primary example of this is through nest depredation (Gregg et al. 1994; Conway and Martin 2000; Chalfoun et al. 2002; Holloran et al. 2005; Stephens et al. 2005; Moynahan et al. 2007). Nest success, often defined as having $\geq 1$ egg hatch, is

\footnotetext{
* Correspondence: stephen@haydenwing.com

${ }^{1}$ Hayden-Wing Associates, LLC, 2308 South 8th Street, Laramie, WY, 82070, USA

Full list of author information is available at the end of the article
}

influenced strongly by the choices females make in terms of nest placement because local and landscapelevel features of the nest site are correlated with susceptibility to depredation (Lima 2009; Conover et al. 2010). Often, females select for screening cover at the nest site to reduce detection by visually oriented predators. In certain situations, ground-nesting birds can place nests in favorable settings to reduce both visual and olfactory detection, but many times, the selection for concealment from visually oriented predators occurs at the expense of olfactory detection (Conover and 
Borgo 2009; Conover et al. 2010). Olfactory detection is difficult to minimize through nest placement. Unlike visual detection, which is a function of structural cover, detection via olfaction is generally a function of weather conditions (i.e., temperature, moisture, and wind), which can facilitate scent production or enhance a predator's capacity to detect scent (Gutzwiller 1990; Dritz 2010). Therefore, we considered both spatial and nonspatial attributes on nest survival because spatial attributes (e.g., cover, topography, and anthropogenic features) can either aid or hinder predators with detection of nests while nonspatial variables (e.g., weather) may facilitate predators in finding nests through olfaction.

Concomitantly, fragmentation of the landscape influences predation and nest success (Chalfoun et al. 2002; Stephens et al. 2003) by providing predators with additional habitat features beneficial to their life history (i.e., subsidization). Artificial structures (e.g., infrastructure, transmission lines, disturbed ground, etc.) can increase the abundance, diversity, or hunting efficiency of predators using the area (Larivière et al. 1999; Coates and Delehanty 2010). Risk of predation may be exaggerated in these areas. Once predators exploit a landscape, predators may alter their behavior at finer spatial scales that allow them to concentrate search behaviors within specific areas (Holloran and Anderson 2005). For instance, during nesting season, predators learn to look for cues of female behavior (Burhans et al. 2002) that can lead them to the nest site. Predators also use search images (Nams 1997; Chalfoun and Martin 2009) developed from previously successful depredation events. Therefore, ground-nesting species such as greater sagegrouse (Centrocercus urophasianus; hereafter sagegrouse) that spend most of their time at the nest site during incubation may become increasingly vulnerable to predation in landscapes that have been altered by human development. Risk of predation may increase in altered landscapes because human development typically results in changes to predator communities, abundance, or behavior (Chalfoun and Martin 2009).

The sage-grouse is a sagebrush-obligate species of conservation concern that was considered for listing under the Endangered Species Act. However, the listing of sage-grouse as threatened or endangered within the United States was found to be warranted, but the listing of sage-grouse was precluded by higher priority actions (United States Fish and Wildlife Service 2010). Yet still, many portions of the sage-grouse's range are experiencing large-scale alterations. Some alterations that historically have contributed to the population decline in sagegrouse include predation, pesticides, sagebrush removal, grazing, and fire (Connelly and Braun 1997). More recent declines in population numbers of sage-grouse and other sagebrush-obligate species in Wyoming have been linked to large-scale development of the landscape for energy, particularly underground reserves of oil and natural gas (Lyon and Anderson 2003; Walker et al. 2007; Becker et al. 2009; Harju et al. 2010; Gilbert and Chalfoun 2011). This study focuses on a sensitive sagebrush-obligate species in an environment undergoing human development (i.e., oil and gas development) that has experienced population declines range-wide (Connelly and Braun 1997; Schroeder et al. 2004) and is exposed to a diversity of predators. Predators of sagegrouse (including nests) included common raven (Corvus corax), golden eagle (Aquila chrysaetos), coyote, (Canis latrans), red fox (Vulpes vulpes), American badger (Taxidea taxus), bobcat (Lynx rufus), and striped skunk (Mephitis mephitis).

We studied predator-prey behavior in a changing environment to uncover factors influencing demographic performance of a sensitive ground-nesting species. The analytical methodology was based on a priori knowledge of prey resource selection and predator behavior, which included spatial variables such as landscape features and nonspatial variables that included weather. Landscape features are important to the daily survival rate [DSR] of nests because birds can select habitat structure that aids or inhibits predator search behavior or that provides physical impediments and nest concealment (i.e., visual obscurity; Chalfoun and Martin 2009; Lima 2009). Additionally, some predators use olfaction to locate nests (Storaas 1988), which can be facilitated by favorable weather conditions (Conover 2007; Moynahan et al. 2007; Conover et al. 2010; Dritz 2010). The objectives of this paper were to (1) identify landscape features and weather patterns important to DSR of nests, (2) determine how landscape features and weather patterns influence depredation of nests in an area where portions of the landscape are undergoing alterations due to energy development, and (3) develop user-friendly models (generalized linear mixed models) to account for the hierarchical structure of the data set and to model fixed and random effects. We discuss these findings within the context of what is known about nest survival of sage-grouse, variables influencing success, and potential mechanisms that facilitate predators in locating nests. We also offer statistical code for analyzing nest survival data that contains fixed and random effects and that can account for the hierarchical structure of the data and the correlation within the data set.

\section{Methods}

\section{Study area}

The study area included $5,625 \mathrm{~km}^{2}$ of the Wind River Basin in central Wyoming, USA (Figure 1). Elevations range from 1,478 to $2,776 \mathrm{~m}$ with variable topography (gently sloping flats, cut banks, dry washes, steep slopes, 


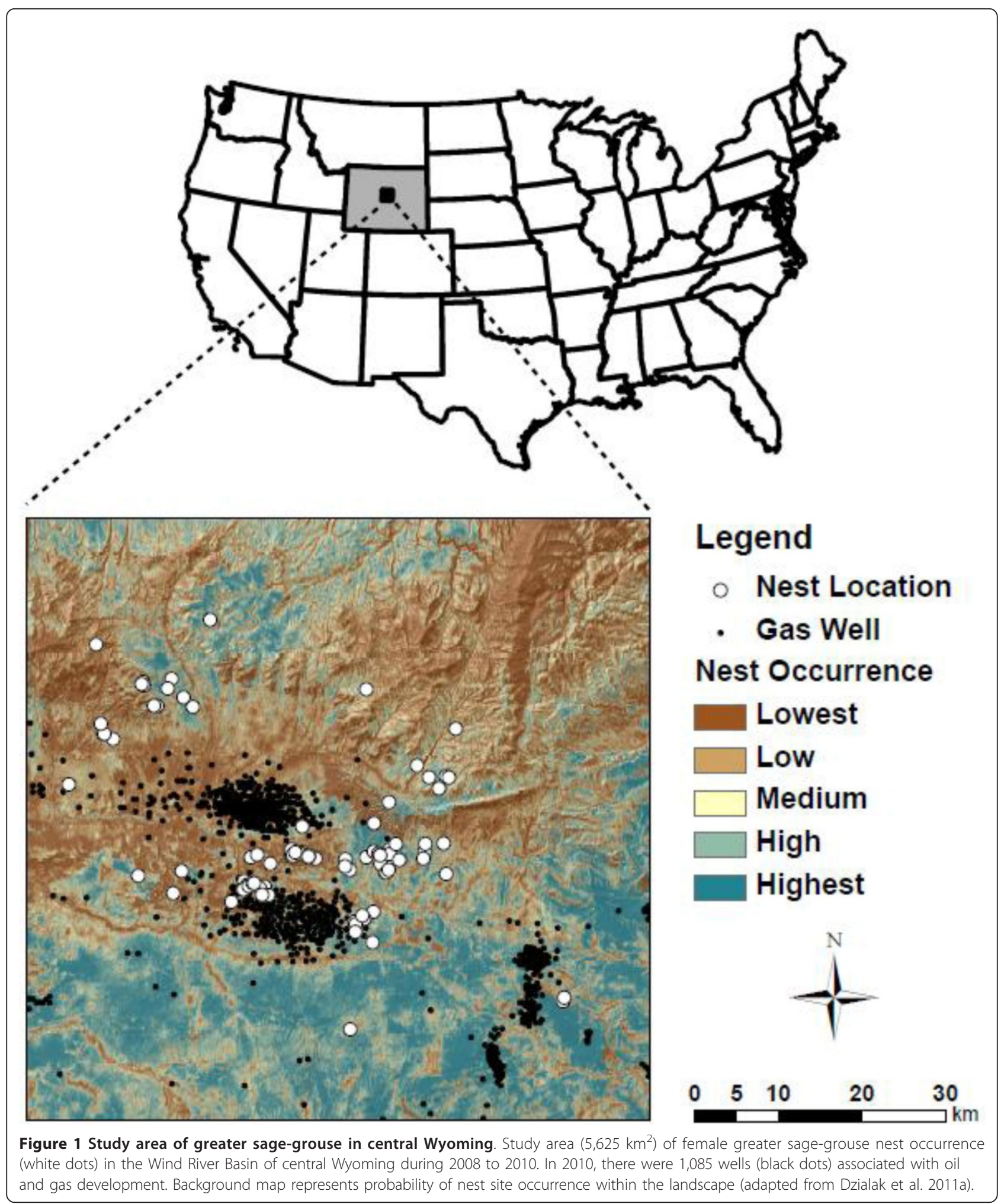

and rocky canyons). Average maximum and minimum temperature during the study period (April to July; hereafter nesting season) was $34.3^{\circ} \mathrm{C}$ and $10.8^{\circ} \mathrm{C}$, respectively. Total precipitation during the nesting season was 19.4 cm in 2008 (Fales Rock, WY, USA; http://www.raws.dri. edu/cgi-bin/rawMAIN.pl?wyWFAL), $12.0 \mathrm{~cm}$ in 2009, and $12.6 \mathrm{~cm}$ in 2010 . Weather data during the nesting seasons of 2009 and 2010 were collected using Vantage 
Pro2 ${ }^{\mathrm{TM}}$ Precision Weather Stations (Davis Instruments Corporation, Hayward, CA, USA) that were located centrally within the study area (Figure 1).

Plants common to the area included Wyoming big sagebrush (Artemisia tridentata subsp. wyomingensis), basin big sagebrush (A.t. subsp. tridentata), mountain big sagebrush (A.t. subsp. vaseyana and $A$. $t$. subsp. pauciflora), little sagebrush (A. arbuscula subsp. arbuscula), Patterson's wormwood (A. pattersonii), black greasewood (Sarcobatus vermiculatus), yellow rabbitbrush (Chrysothamnus viscidiflorus), winterfat (Ceratoides lanata), shadscale saltbush (Atriplex confertifolia), limber pine (Pinus flexilis), and rocky mountain juniper (Juniperus scopulorum) (http://plants.usda.gov/java/).

The study area encompassed pre-existing and expanding development of energy resources. Oil and natural gas development was initiated in the 1920s, but gas development has recently accelerated since the 1990s. In 2008, there were 1,002 wells associated with oil and gas development in the study area. Wells increased 3.2\% from 2008 to $2009(n=1,034)$ and $4.9 \%$ from 2009 to $2010(n=1,085)$.

\section{Capture and handling}

During March and April of 2008 to 2010, we captured sage-grouse on and around leks at night with the aid of spotlights (Wakkinen et al. 1992). Capture also occurred in autumn (September to November) to maintain sample size from dropped collars or fatalities. Females captured in autumn provided data during the nesting season of the following year. We assigned age (yearling $<2$ years; adult $\geq 2$ years) to each female based on the appearance of primaries (Eng 1955; Crunden 1963), and fitted sage-grouse with global positioning system [GPS] collars (30-g ARGOS/GPS Solar PTT-100, Microwave Telemetry, Inc., Columbia, MD, USA) using rumpmounted techniques (e.g., Bedrosian and Craighead 2007). GPS collars had a 3-year operational life and were configured with ultrahigh-frequency beacons for ground tracking and detection of fatality. Collars were programmed with two fix schedules: (1) one fix every 3 h from 0700 to 2200 hours during 16 February to 14 May and (2) one fix every hour during 15 May to 15 July. Animal capture and handling protocols were approved by the Wyoming Game and Fish Department (Chapter 33 Permit \#649).

\section{Nest monitoring}

We used GPS locations (transmitted via ARGOS; www. argos-system.org) to locate nests during egg-laying, which has been found to provide a reliable and precise estimation of nest initiation, incubation, and nest hatch or failure (Dzialak et al. 2011a). First, we examined the spatial pattern of movement by the female during egg- laying, which is characterized by brief visits of $<3 \mathrm{~h}$ to a spatially distinct location (i.e., nest site) every 2 to 3 days for a 9- to 12-day period (Schroeder et al. 1999). Next, we observed that the female was exclusively (or almost exclusively) at the nest location for a complete diel cycle on the first day of incubation. Thus, we used this date as the initiation date of incubation.

We projected the expected hatch date using the average incubation period of 27 days from the first day of incubation (Schroeder et al. 1999). If a female vacated the nest site $>4$ days prior to the projected hatch date, we assumed that the nest was abandoned or failed, and a field crew checked the status of the nest to determine fate (date of first departure used as failure date).

We considered nests successful if $\geq 1$ egg hatched; otherwise, we classified the nest as unsuccessful, noting the date and the age of the nest at failure and assigning a cause of failure (i.e., depredated, other or unknown, and death of female). Successfully hatched eggs (Figure 2) were identified by the presence of a distinct egg cap and an intact egg membrane (initial cracking, or pipping, of the egg typically results in two eggshell fragments, with the smaller fragment called the cap); such features are not typical of depredated eggs (Figure 3; Sargeant et al. 1998).

The spatial data (GPS locations transmitted via ARGOS) allowed us to estimate with high probability the first day of incubation and the date of nest failure or hatch. Last, we were able to monitor the nest status on a daily schedule with GPS data that allowed a straightforward means of modeling DSR of nests (see below). This was an advantage compared to previous studies that conducted periodic checks for nests, discovered nests at various stages, estimated failure date because nests were only periodically rechecked, and used an exponent to account for survival across differing interval lengths (i.e., logistic-exposure model; Shaffer 2004).

\section{Spatial variables: landscape}

Processes on the landscape occur and interact at multiple spatial scales (Wiens 1989), and likely carry-over to influence predator behavior on the landscape because most predators also perceive the landscape at various spatial scales (Chalfoun et al. 2002; Stephens et al. 2005). For these reasons, we use a multi-scalar approach to examine the relationships between DSR of nests and spatial landscape features (i.e., anthropogenic and landscape features, and topography) important to sagegrouse during nesting.

At the nest site (i.e., 15-m spatial scale), we measured shrub canopy and sagebrush canopy coverage using line intercept methods (Canfield 1941). We stretched two 15-m tapes perpendicular to each other using the nest site as the center point (i.e., $7.5 \mathrm{~m}$ on each tape); the 


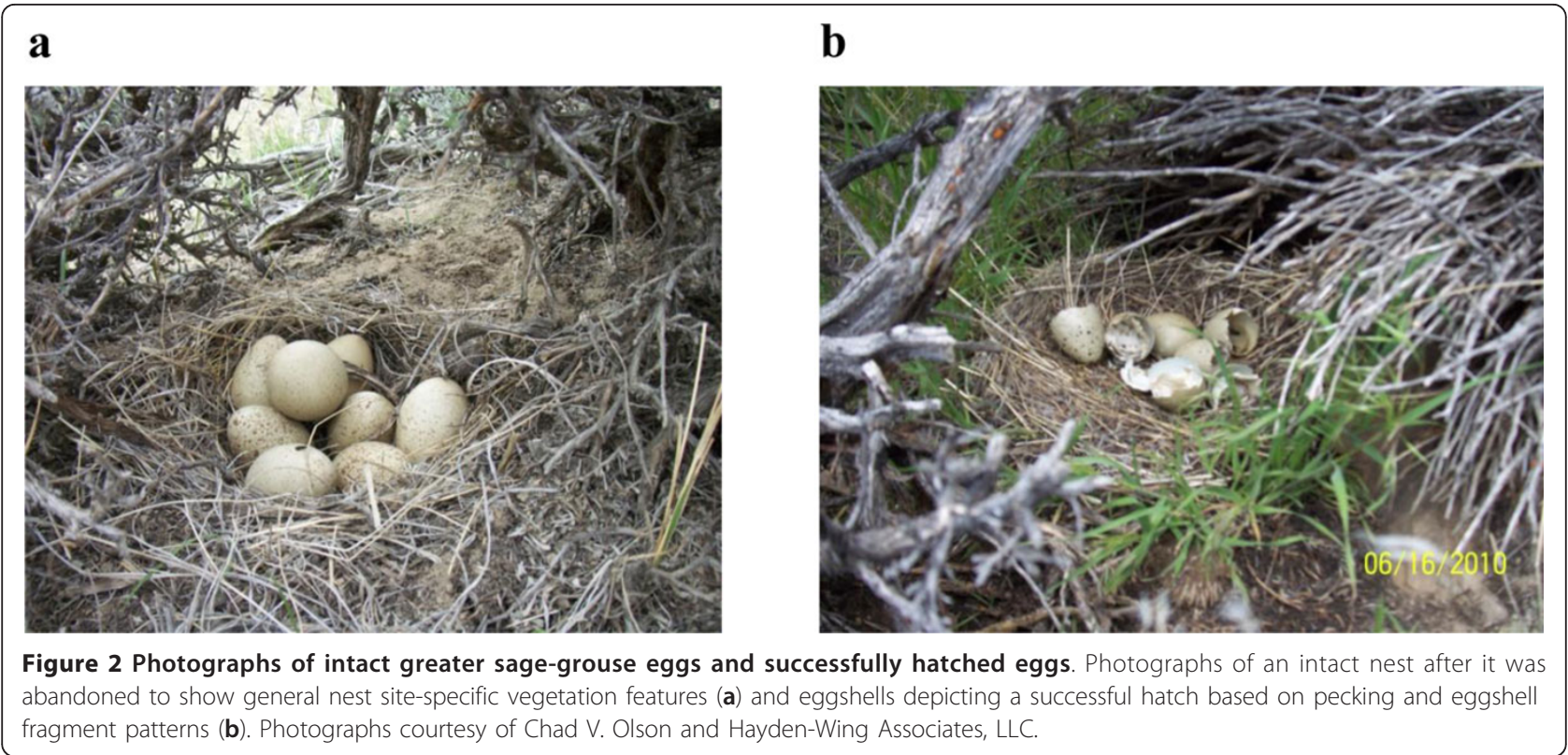

direction of the first line was randomly determined, and the second line was placed perpendicular to the first. From the center point (i.e., the nest site), all shrub species intersecting the transect lines were recorded to species along the $7.5-\mathrm{m}$ section of the line in each direction. Gaps in shrub canopy of $\geq 5 \mathrm{~cm}$ were not recorded. We also measured the percentage of herbaceous vegetation (grass, forbs, and total herbaceous vegetation) canopy coverage using $20 \times 50$-cm Daubenmire plots (Daubenmire 1959). Daubenmire plots were placed along each $15-\mathrm{m}$ line at $1.5-\mathrm{m}$ intervals, which finally resulted in 20 plots. Last, we recorded the species of the shrub within which the nest was located, along with the height (in centimeters) of the shrub.
At larger spatial scales (i.e., $\geq 30 \mathrm{~m}$; see below), we used a geographic information system $\left(\operatorname{ArcGIS}^{\circledR} 10.0\right.$, Environmental Systems Research Institute, Inc., Redlands, CA, USA) to map anthropogenic and landscape features, and topography because these features were known to influence resource selection of sage-grouse (Aldridge and Boyce 2007; Doherty et al. 2008; Dzialak et al. 2011a). Four covariates depicted predominant human modifications of the landscape, distance (in meters) to the nearest oil or gas well, road, residential structure, and energy-related ancillary feature. Data on wells were current through July 2010 and were obtained from the Wyoming Oil and Gas Conservation Commission (http://wogcc.state.wy.us/). We considered the
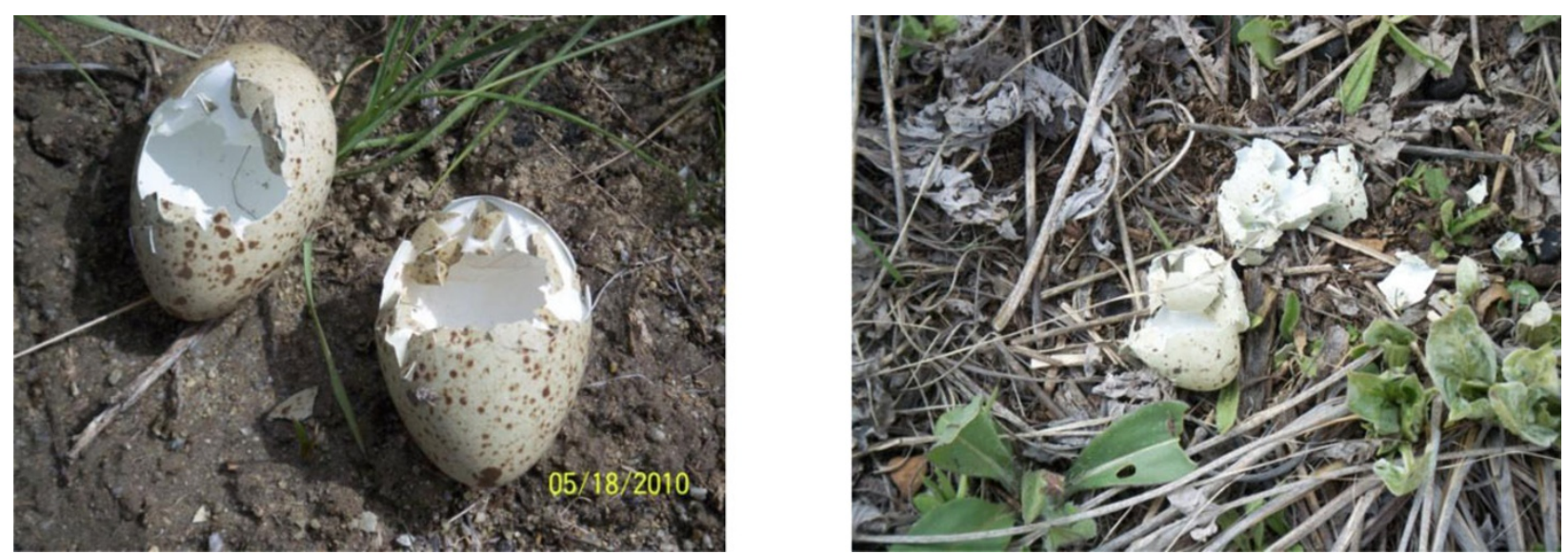

Figure 3 Photographs of depredated greater sage-grouse eggs. Photographs depicting depredated eggs by various nest predators. Patterns are consistent with depredation and not a successful hatch (cf Figure 2b). Photographs courtesy of Chad V. Olson and Hayden-Wing Associates, LLC. 
distance to the nearest well during the year of nesting as well as the distance to wells 1 and 2 years prior to nesting (lag effects; Harju et al. 2010). Roads (paved, improved, and dirt), structures, and ancillary features (e.g., compressor stations, settling ponds, and buildings) were heads-up digitized (1:500 to $1: 2,000$ scale) using National Agriculture Imagery Program aerial photography (1-m resolution).

We mapped five landscape features that depicted predominant vegetation in the study area: percentage (in percent) of sagebrush, shrub, bare ground, litter, and herbaceous vegetation (grass and forbs). We examined these five landscape features at four spatial scales (number of 30-m pixels per side around the nest site, which was located in the center cell); $30 \mathrm{~m}(1 \times 1), 90 \mathrm{~m}(3 \times$ 3), $810 \mathrm{~m}(27 \times 27)$, and $1,590 \mathrm{~m}(53 \times 53)$. The $30-\mathrm{m}$ pixel represented the percentage of each variable and was mapped across the landscape using the Provisional Remote Sensing Sagebrush Habitat Quantification Products for Wyoming database, which was developed by the United States Geological Survey (Homer et al. 2010). Larger spatial scales (i.e., 90, 810, and 1,590 m) allowed us to calculate an average percentage of each variable around the nest site.

Last, we mapped five covariates that depicted topography and other natural features: elevation (in meters), heat load index (Dzialak et al. 2011a), slope (in percent), terrain roughness (standard deviation [SD] of elevation), and distance (in meters) to mesic areas. Elevation, slope, and terrain roughness were generated using a 10-m digital elevation model [DEM]. Slope was measured in degrees, and terrain roughness was calculated as the SD of elevations from the DEM at 90-, 810-, and 1,590-m scales. We calculated the distance to the nearest mesic area, which included streams, seeps, springs, impoundments, irrigated areas, and water discharge sites; the type of mesic area was developed using Feature Analyst $\left.{ }^{(}\right) 4.2$ (Visual Learning Systems, Inc., 2008) for ArcGIS ${ }^{\circledR} 9.3$ (ESRI, Redlands, CA, USA). We used Spatial Analyst in ArcGIS ${ }^{\circledR} 10.0$ to calculate raster values and to extract values from raster data to location data for all covariates. See Visual Learning Systems, Inc. (2008) and Webb et al. (2011) for details on using Feature Analyst, and Dzialak et al. (2011a) for a more complete description of covariates, data sources, and methods.

\section{Nonspatial variables: weather}

We also considered that nonspatial variables such as weather may facilitate predators in finding nests because weather factors such as temperature, moisture, and air movements influence scent production as well as detection (Gutzwiller 1990). We obtained daily readings for maximum, minimum, and average temperatures (in degree Celsius); humidity (in percent); average and maximum wind speeds (in kilometers per hour); and precipitation (Conover 2007; Moynahan et al. 2007; Conover et al. 2010; Dritz 2010); precipitation was converted to a binomial variable that indicated the presence or absence of rainfall $\geq 0.025 \mathrm{~cm}$. The aforementioned weather variables likely facilitate or inhibit olfaction in predators while searching for a prey. During nesting seasons of 2009 and 2010, we installed and used weather stations (Vantage Pro2 ${ }^{\mathrm{TM}}$ Precision Weather Station, Davis Instruments, Hayward, CA, USA) that were located centrally within the study area (Figure 1). We installed centrally located weather stations after the nesting season of 2008; therefore, we did not have centrally located weather data during 2008. However, during 2008, we obtained nearby weather data from the Western Regional Climate Center (Fales Rock, WY, USA; http://www.raws.dri.edu/cgi-bin/rawMAIN.pl? wyWFAL); this station was $6.4 \mathrm{~km}$ south of our study area (Figure 1).

\section{Model development and analysis}

Two additional variables were modeled: the Julian date and the age of the nest. The Julian date was modeled because nest survival may be related to when the nest was initiated. Similarly, the age of the nest (number of days since incubation began) was modeled to examine whether nests early or late in incubation had a greater probability of surviving. Before implementing a hierarchical variable selection approach, we created quadratic terms (quadratic $=$ original $^{2}$ ) for the following: the Julian date (first day of incubation); age of the nest (days since incubation began); temperature; humidity; wind speed; shrub height; percentage of bare ground, litter, forbs, grass, total herbaceous vegetation, sagebrush, and shrub; terrain roughness; elevation; and slope at all spatial scales examined. We developed quadratic terms because animals often avoid the lowest and highest values associated with a given landscape feature (Aldridge and Boyce 2007; Johnson et al. 2004; Stephens et al. 2005; Dzialak et al. 2011a). We also natural log-transformed all distance variables (i.e., distance to wells, structures, ancillary features, roads, and mesic habitat) to allow for a decreasing magnitude of influence with increasing distance. To assure that a natural log transformation [ln] was not attempted on a cell with a value $=0$, we added 0.1 to all original values $($ new $=\ln ($ original +0.1$)$ ). Last, we created a new precipitation variable that indicated whether precipitation occurred 1 day prior (i.e., a lag event).

We implemented a four-step hierarchical variable inclusion approach to reduce the number of variables in the final model. First, we used an information-theoretic approach (Burnham and Anderson 2002) to evaluate each landscape variable at multiple spatial scales (e.g., 
nest site (15-m scale), 30, 90, 810, and 1,590 m). We selected the spatial scale and term for each landscape variable using Akaike's information criterion [AIC] adjusted for small sample size [AICc] (Burnham and Anderson 2002). We retained the spatial scale and term for each variable with the lowest AICc. We used generalized linear mixed models [GLMM] (PROC GLIMMIX, SAS $^{\circledR}$ 9.2, SAS Institute Inc., Cary, NC, USA) and the Laplace method of approximating the log likelihood to determine the most appropriate spatial scale and term for each landscape variable (Appendix 1). Data were analyzed using a logistic regression framework where nest fate (survived or failed) on each day was analyzed as a binary response variable ( $1=$ survived; 0 = failed); modeling daily nest fate as a binary response was the basis for estimating the probability of daily nest survival (i.e., DSR of nests). We included three random effect statements to model the hierarchical structure of the data set (Appendix 1). Random effects were used to model the fate of nests because nest fates may be correlated within (1) nesting attempts and individual birds (nest identification 'nested' within bird identification; NID(BIRD)), (2) individuals and years (bird identification 'nested' within year; BIRD(YEAR)), and (3) years (Appendix 1). We used a binary distribution, a logit-link function (constraining DSR of nests between 0 and 1), and a variance components-covariance structure for random effects (Appendix 1). Second, after only one spatial scale and term was selected for each landscape variable, we assessed the correlation among remaining landscape variables using PROC CORR (SAS ${ }^{\circledR}$ 9.2; SAS Institute Inc.) and eliminated covariates for $r \geq 0.5$; the variable providing the simplest biological interpretation was retained. Third, we considered the remaining variables to comprise a 'full' landscape model. Using the GLMM described above, we assessed the influence of all covariates in the full landscape model simultaneously on daily nest fate (binary response variable) to estimate the probability of DSR of nests. We removed any variable where $P>0.1$, thus creating a reduced model for the last step in building the most parsimonious final model of DSR of nests. Last, we added weather variables to the final landscape model to determine if the addition of weather variables improved model fit (sensu Dinsmore et al. 2002). Thus, we refer to the final landscape model as a null model for assessing additional model building. We considered only models with AICc values lower than the null landscape model or within $2 \Delta \mathrm{AICc}$ units of the null landscape model. Weather variables that resulted in lower AICc values were combined to create a model with multiple weather variables. We also assessed the relative plausibility of models in the set of candidate models using Akaike weights $\left[w_{i}\right]$, with the best model having the highest $w_{i}$ (Burnham and Anderson 2002). We built the landscape model first because female greater sage-grouse can make decisions on nest site location and structure to aid in concealment from predators. However, weather is an uncontrollable influence on nest fate that may facilitate predation; thus, these variables were added last to assess their strength on influencing DSR of nests.

\section{Results}

During the 3 -year study, we monitored 83 nests initiated by 67 individual females (Table 1). One female was killed while off the nest (approximately $600 \mathrm{~m}$ from the nest as determined by GPS locations), whereas all others were killed while on the nest. We analyzed data on the one female that was killed approximately $600 \mathrm{~m}$ from the nest because inclusion of this bird did not change the magnitude or direction of the relationships with landscape covariates.

We were interested only in DSR of nests during incubation, so we excluded four nests that failed during egglaying and one nest that survived to 27 days, but was considered unsuccessful because no eggs hatched. Of the four birds that had a failed nest during egg-laying, three birds incubated on their second attempt whereas the remaining bird initiated two incubation attempts after the failed egg-laying attempt.

Considering only incubation attempts of the 67 individual females, 14 females attempted a second nest and 2 females attempted to incubate three nests within a season. Ten incubation attempts were unsuccessful for both the first and second attempts (71.4\%; 10 of 14), while four second attempts were successful after an

Table 1 Sample sizes and nest fates of greater sage-grouse in central Wyoming

\begin{tabular}{|c|c|c|c|c|c|c|c|c|c|}
\hline \multirow[b]{2}{*}{ Year } & \multicolumn{2}{|c|}{ Sample size ${ }^{a}$} & \multicolumn{2}{|c|}{ Dates $^{b}$} & \multicolumn{4}{|c|}{ Nest fate ${ }^{a}$} & \multirow[t]{2}{*}{ Apparent survival } \\
\hline & Females & Nests & First & Last & Hatched & Depredated & Other & Hen-killed & \\
\hline 2008 & 17 & 18 & 26 April & 11 June & 5 & 13 & 0 & 0 & 0.28 \\
\hline 2009 & 23 & 26 & 22 April & 14 June & 8 & 15 & 1 & 2 & 0.31 \\
\hline 2010 & 27 & 39 & 21 April & 12 July & 11 & 22 & 0 & 6 & 0.28 \\
\hline Total & 67 & 83 & - & - & 24 & 50 & 1 & 8 & $\bar{x}=0.29$ \\
\hline
\end{tabular}

${ }^{a}$ Annual sample sizes of female greater sage-grouse and nests, and corresponding nest fates, on the 5,625-km² study area in the Wind River Basin in central Wyoming, USA. ' Dates listed are for the initiation of the first nest (i.e., First) and the hatching or depredation of the last nest (i.e., Last). Nests of female greater sage-grouse that died during incubation were considered failed nests. 'Apparent annual nest survival (i.e., successful hatch) was calculated as 'Hatched'/'Nests.' 
unsuccessful first attempt $(28.6 \% ; 4$ of 14$)$. The two females that attempted to incubate three nests were successful during the third attempt. The earliest incubation date was 21 April, and the latest date of nest failure or hatch was 12 July (Table 1 ).

Average apparent nest survival was $28.9 \%$ (24 of 83 ) and ranged from 0.28 to 0.31 during the three nesting seasons (Table 1). Nest predation was the most significant form of mortality $(84.7 \% ; 50$ of 59$)$ followed by direct predation of the female $(13.6 \% ; 8$ of 59$)$ that resulted in nest failure and other sources of nest destruction $(1.7 \%$; 1 of 59 ; Table 1$)$. In total, predation accounted for $98.3 \%$ of nest failures.

Selection of specific covariates for each class of landscape, topographic, and anthropogenic variables revealed that site-specific covariates were the most important (i.e., $\leq 30 \mathrm{~m}$ ), except for roughness, which was the most important at the largest spatial scale examined (i.e., 1,590 m; Table 2). Although we did not model the type of shrub species at the nest site, we did observe that nests were built under four species of shrubs: big sagebrush species $(76.2 \%)$, little sagebrush (13.6\%), yellow rabbitbrush (8.1\%), and greasewood (2.1\%). After removing correlated covariates and variables not important in the landscape model $(P>0.1)$, we retained two landscape covariates (percentage of shrub cover at nest site (15-m scale) and distance to mesic habitat) and two anthropogenic covariates (distance to oil and gas wells and distance to roads; Table 2). We also retained the date of initiation of the incubation process (Julian date) and the nest age in the model (Table 2). The final landscape model thus included seven covariates, including the intercept.

We used the final landscape model as the null model from which to base the influence of weather variables when added to the model. We found that adding weather variables resulted in six models with a lower AICc $(n=2)$ or within 2 AICc units of the null model ( $n=4$; Table 3 ). The best model for daily nest survival included 10 parameters and had a model weight of 0.774 , which was 10.5 times more likely to be the best approximating model compared to the next best model $\left(w_{i}=0.074\right.$; Table 3$)$. All other models had $w_{i} \leq 0.053$ (Table 3). Therefore, we considered only the best model when calculating coefficient estimates and for plotting relationships between DSR of nests and the covariates. The Pearson chi-square statistic divided by degrees of freedom indicated that models were specified reasonably (0.66 to 1.03 ; Table 3 ).

The logistic regression equation for DSR of nests using the best model (see Table 3) was (standard error [SE] reported in parentheses after the coefficient estimate):
Table 2 Variables considered important to greater sagegrouse nest survival in central Wyoming

\begin{tabular}{|c|c|c|}
\hline Variable & Covariate & $\begin{array}{c}\text { Scale } \\
(\mathrm{m})\end{array}$ \\
\hline \multicolumn{3}{|l|}{ Vegetation } \\
\hline Shrub height (-) & Height of shrub $(\mathrm{cm})$ at nest ${ }^{a}$ & $15^{\mathrm{b}}$ \\
\hline $\begin{array}{l}\text { Bare ground }(-, \\
+)\end{array}$ & Percentage (\%) of bare ground ${ }^{c}$ & $30^{\mathrm{d}}$ \\
\hline Litter $(-,+)$ & Percentage (\%) of litter ${ }^{c}$ & 30 \\
\hline Forbs (+) & Percentage (\%) of forb cover ${ }^{a}$ & 15 \\
\hline Grass (-) & Percentage (\%) of grass cover ${ }^{a}$ & 15 \\
\hline $\begin{array}{l}\text { Total } \\
\text { herbaceous (-) }\end{array}$ & $\begin{array}{l}\text { Percentage (\%) of total herbaceous } \\
\text { cover }^{\mathrm{a}}\end{array}$ & 15 \\
\hline Sagebrush $(-,+)$ & Percentage (\%) of sagebrush cover ${ }^{c}$ & 15 \\
\hline Shrubs (+) & Percentage (\%) of total shrub cover ${ }^{a}$ & 15 \\
\hline Mesic (+) & $\begin{array}{l}\text { Distance }(m) \text { to mesic habitat year of } \\
\text { nest }^{\text {e }}\end{array}$ & $N / A$ \\
\hline \multicolumn{3}{|l|}{ Topography } \\
\hline Elevation $(-,+)$ & Elevation $(m)^{c}$ & 30 \\
\hline Slope $(+)$ & Slope $(\%)^{a}$ & 30 \\
\hline Roughness (+) & Roughness index (SD of elevation) ${ }^{a}$ & $1,590^{\mathrm{c}}$ \\
\hline \multicolumn{3}{|l|}{ Anthropogenic } \\
\hline $\begin{array}{l}\text { Oil and gas } \\
\text { wells }(+)\end{array}$ & Distance $(m)$ to wells year of nest ${ }^{e}$ & N/A \\
\hline Structures (-) & Distance $(m)$ to structures year of nest $\mathrm{e}^{\mathrm{e}}$ & N/A \\
\hline $\begin{array}{l}\text { Ancillary } \\
\text { features (-) }\end{array}$ & $\begin{array}{l}\text { Distance }(m) \text { to ancillary features year } \\
\text { of nest }^{\mathrm{e}}\end{array}$ & N/A \\
\hline Roads (-) & Distance $(m)$ to roads year of nest ${ }^{a}$ & $N / A$ \\
\hline \multicolumn{3}{|l|}{ Others } \\
\hline $\begin{array}{l}\text { Initiation date } \\
(+)\end{array}$ & $\begin{array}{l}\text { Julian date for first day of nest } \\
\text { incubation }^{\mathrm{a}}\end{array}$ & N/A \\
\hline Nest age $(-)$ & Age of nest (in days) ${ }^{a}$ & $N / A$ \\
\hline
\end{tabular}

${ }^{\mathrm{a}}$ Linear term. ${ }^{\mathrm{b}}$ Refers to on-the-ground measurements of vegetation at the nest site using either Daubenmire plots (forbs, grass, and total herbaceous vegetation) or line transects (percentage of sagebrush and shrub canopy cover). ' Linear + quadratic term. ${ }^{\mathrm{d}}$ Spatial scales depicted as an area (e.g., 30 or $1,600 \mathrm{~m}$ ) using remotely sensed imagery and heads-up digitizing to

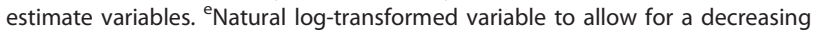
magnitude of influence with increasing distance. Variables selected from a suite of variables at multiple spatial scales (the spatial scale for each variable with the lowest AICc was retained) that were considered to influence nest survival of female greater sage-grouse in the Wind River Basin in central Wyoming, USA. Variables in italicized text were entered into a landscape model after variable reduction based on AICC, correlation (PROC CORR; SAS ${ }^{\mathbb{R}}$ $9.2)$, and non-significance $(P>0.1)$, and used as a null landscape model for testing the influence of weather on daily nest survival. Signs (positive or negative) in parentheses next to landscape variables represent the relationship between the particular variable and the probability of DSR (when two signs occur, the first represents the linear relationship and the second represents the quadratic relationship). SD, standard deviation; N/A, not applicable.

$\operatorname{logit}(\widehat{S})=-3.3181(2.0704)+0.0052(0.0112) \times$ julian date $-0.0559(0.0498) \times$ age of nest $+0.0027(0.0229) \times$ percentage of shrubs $+0.6882(0.3052) \times$ ln distance to wells -0.0001 $(0.0001) \times$ distance to roads $+0.2813(0.1639) \times \ln$ distance to mesic habitat $+0.0178(0.0287) \times \max$ wind speed $0.0004(0.0003) \times \max$ wind speed $^{2}-0.7551(0.3167) \times 1$-day lag in precipitation $(0=$ no rain; $1=$ rain $\geq 0.025 \mathrm{~cm})$. 
Table 3 Model selection results that describe DSR of greater sage-grouse in central Wyoming

\begin{tabular}{|c|c|c|c|c|c|}
\hline \multirow[t]{2}{*}{ Model } & \multirow[t]{2}{*}{$K$} & \multirow[t]{2}{*}{ AICc } & \multicolumn{2}{|c|}{$\triangle \mathrm{AICc}$} & \multirow[t]{2}{*}{$w_{i}$} \\
\hline & & & From the best & From the null & \\
\hline Landscape + max wind (linear) + max wind (quadratic) + precipitation (1-day lag) & 10 & 470.29 & 0 & -5.36 & 0.774 \\
\hline Landscape + max wind (linear) + max wind (quadratic) & 9 & 474.98 & 4.69 & -0.67 & 0.074 \\
\hline Landscape & 7 & 475.65 & 5.36 & 0 & 0.053 \\
\hline Landscape + max wind (linear) & 8 & 476.96 & 6.67 & 1.31 & 0.028 \\
\hline Landscape + average wind (linear) + average wind (quadratic) & 9 & 477.10 & 6.81 & 1.45 & 0.026 \\
\hline Landscape + average wind (linear) & 8 & 477.24 & 6.95 & 1.59 & 0.024 \\
\hline Landscape + precipitation (1-day lag) & 8 & 477.46 & 7.17 & 1.81 & 0.021 \\
\hline
\end{tabular}

Model selection results for the best approximating model of DSR of nests for female greater sage-grouse in the Wind River Basin in central Wyoming, USA. Model selection was based on $\triangle \mathrm{AICC}$ using the landscape model (see Table 2) as the null model from which to base model fit with the addition of weather variables. Only models $\leq 2 \Delta \mathrm{AICC}$ units from the null landscape model are reported, unless AICc was lower than the null landscape model. $K$, number of parameters in model; AICc, Akaike's information criterion corrected for small sample size; $w_{i}$ Akaike weights; max, maximum.

Overall DSR of nests was 0.95 , resulting in an estimated nest survival rate of $25.0 \%$, while holding all covariates constant at their mean values and considering a 1-day lag in precipitation. Average apparent nest survival (28.9\%) was similar to the most parsimonious model above (25.0\%).

DSR was associated positively with the Julian date (Figure 4a), percentage of shrub cover (Figure 4b), distance to wells (Figure 4c), and distance to mesic habitat (Figure 4d), but was associated negatively with nest age, distance to roads, and maximum wind speed (Figure $4 \mathrm{e})$. On average, females that successfully incubated a clutch initiated incubation 5 days later (successful = $131.8 \pm 2.9 \mathrm{SE}$; unsuccessful $=126.4 \pm 1.5 \mathrm{SE})$, located nests under greater shrub cover (successful $=23.7 \% \pm$ $2.1 \mathrm{SE}$; unsuccessful $=18.8 \% \pm 1.1 \mathrm{SE}$ ), were farther from wells (successful $=4,445 \mathrm{~m} \pm 656.8 \mathrm{SE}$; unsuccess$\mathrm{ful}=3,353 \mathrm{~m} \pm 440.4 \mathrm{SE}$ ) and mesic areas (successful = $1,060.2 \mathrm{~m} \pm 119.0 \mathrm{SE}$; unsuccessful $=895.5 \mathrm{~m} \pm 67.7$ $\mathrm{SE}$ ), but marginally closer to roads (successful $=2,568$ $\mathrm{m} \pm 615.2$ SE; unsuccessful $=2,693 \mathrm{~m} \pm 330.0$ SE). Precipitation was analyzed as a binomial variable; thus, DSR of nests was lower the day following precipitation events of $\geq 0.025 \mathrm{~cm}$. The relationships between DSR of nests and distance to wells, distance to mesic habitat, and maximum wind speed revealed thresholds in the effect of those variables on DSR of nests. DSR of nests increased significantly when placed 250 to $1,600 \mathrm{~m}$ from the nearest oil or gas well (Figure 4c). In relation to the distance from mesic habitat, DSR of nests was lowest when the nest was within $50 \mathrm{~m}$ of the nearest mesic area, leveling off after reaching the 50-m threshold (Figure 4d). Last, DSR of nests began to drop rapidly once wind speeds reached or exceeded approximately $60 \mathrm{kph}$ (Figure 4e).

\section{Discussion}

In this study, we used the movement behavior of female sage-grouse obtained from GPS collar data to identify initiation of incubation and subsequent failure or hatching of the nest. Unlike nest monitoring efforts based on conventional telemetry, the approach we used allowed nests to be monitored (1) remotely without observer influence on incubation and (2) on a daily cycle, so the exact date of nest hatch or failure was known. Based on model weights $\left(w_{i}\right)$, there was little model uncertainty (Burnham and Anderson 2002) as to the selection of the best model among all candidate models. Within this landscape, nest-site placement by female sage-grouse was influenced by landscape variables at multiple spatial scales (Dzialak et al. 2011a); however, DSR of nests was most influenced by nest site-specific variables (area $\leq 30$ $\times 30 \mathrm{~m}$ ), similar to another study by Manzer and Hannon (2005). This finding is in contrast to other studies which found that landscape-level variables were most influential on the success of nests by ground-nesting birds (Stephens et al. 2005; Moynahan et al. 2007). Examining the variables that were included in the final model revealed potential mechanisms (i.e., visual and olfactory) that predators used to locate nests when considering that nest depredation and direct predation of the incubating female were the most common sources of nest failure. Last, the modeling approach used offers a simplified and unified framework for modeling nestand time-specific covariates, fixed and random effects, complex hierarchical data structures, and multiple relationships (e.g., linear and quadratic) of the independent variables, and to account for the correlation of multiple measurements on the same bird and nest (Appendix 1).

Female movement and activity, collected using GPS collars, allowed researchers to find all nests beginning on day 1 of incubation, a phenomenon that rarely occurs in field studies (Shaffer 2004). This approach offered several advantages. First, we reduced any confounding effects of nest age because all nests were found and observed starting on day 1 of incubation (see Dinsmore et al. 2002 for a discussion on nest age as a confounding effect). Typically, apparent estimates of 


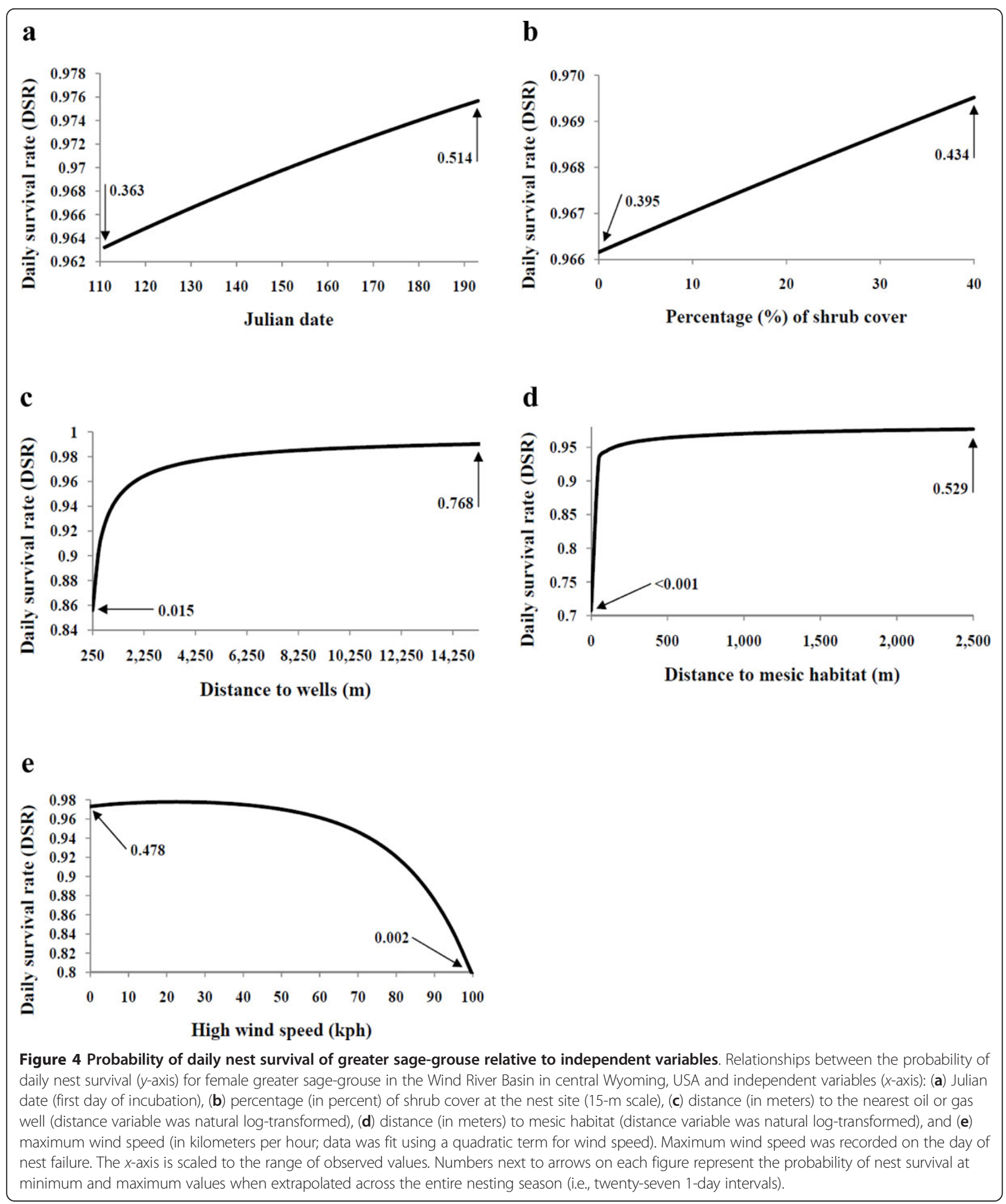

nest survival are biased (Moynahan et al. 2007), but under the conditions of equal detection probability between active and inactive nests (those that have already failed), apparent nest survival is relatively unbiased (Shaffer 2004), as we saw from our estimates. Therefore, we reduced the bias of estimates of nest survival because we found all nests (once incubation was initiated) before they had a chance to fail. Second, we 
modeled true DSR (interval = 1 day). Because we modeled true DSR, time-specific covariates, such as weather, were estimated with high precision (Shaffer 2004). Third, observer disturbance was minimized, thereby reducing this potentially confounding factor as a source of nest failure. Fourth, most previous studies used veryhigh-frequency transmitters to locate birds on nests with variable search schedules, thereby finding nests after the first day of incubation and thus biasing estimates of survival high because nests failing early were not detected. Crawford et al. (2004) reported an average nest survival (defined as the probability of hatching $\geq 1$ egg) rate of $47.4 \%$ ( $n=14$ studies). Potentially then, the aforementioned average nest survival estimate could be biased high. Thus, our estimate of nest survival (25\%) may be more accurate, albeit lower, because nests were detected on day 1 of incubation. Last, even when nests are rechecked periodically, the GLMM approach we present can still account for variable time intervals by using methods (i.e., the link function contains an exponent (1/ $t$, where $t=$ length of observation interval) in the numerator and denominator) similar to the logisticexposure model (see Equation 2 in Shaffer 2004).

Other researchers hypothesized that DSR of nests would be lower in the early stages of incubation because vulnerable nests would be depredated earlier (Klett and Johnson 1982; Coates and Delehanty 2010); thus, we incorporated a time-dependent covariate (e.g., nest age) into models. However, we observed the opposite trend; nests had a higher probability of daily survival during early stages of incubation compared with later stages of incubation. This finding supports the idea that predators develop search images whereby predators may learn to cue in on female behavior during the course of incubation. Female attendance (Cao et al. 2009) or activity (Burhans et al. 2002) at the nest might draw the visual attention of predators to the site of the nest. More specifically, nests failing later in incubation may simply be related to the risk associated with exposure (Grant et al. 2005) where eggs exposed to the risk for longer periods will have more time to be detected and depredated. It is also plausible that the relationship between DSR of nests and nest age could be a function of predators cuing in on the nest due to olfaction from the female (Storaas 1988) because more odor will be emitted and bound to nest substrates (Conover 2007) the longer a female remains in one area (i.e., nest site).

In this study, there were several landscape features that influenced DSR of nests, particularly nest site-specific variables $(\leq 30 \mathrm{~m})$. Most of these features interacted with predator behavior to reduce or facilitate depredation of the nest. These features are important to consider because nest failure in most avian species, particularly ground-nesting birds, is due primarily to predation (Gregg et al. 1994; Conway and Martin 2000; Chalfoun et al. 2002; Holloran et al. 2005; Stephens et al. 2005; Moynahan et al. 2007), as it was in this study. The amount (i.e., percentage) of shrub cover around the nest site was important for reducing depredation. Sagebrush (Artemisia spp.) was the primary brush species comprising shrub canopy cover in our study, and it is well known that the amount or height of sagebrush around nest sites of sage-grouse is important for survival (Connelly et al. 1991; Schroeder et al. 1999; Coates and Delehanty 2010). DSR of nests increased linearly in relation to canopy cover of shrubs at the nest site. The positive relationship observed in this study offers support that shrubs can provide physical impediments to the nest. In addition, shrubs can serve as screening cover to reduce visual detection by terrestrial predators and canopy cover to reduce depredation by aerial predators. In general, greater concealment at the nest site leads to a lower probability of nest discovery by visionbased predators (Lima 2009). Thus, shrubs function primarily as a visual impediment to most predators of nests, albeit shrubs also can function to create turbulence (measure of variance of wind speed and direction) and reduce the odor plume of the bird nesting within (Conover 2007).

Although nest depredation often is a function of visual detection of the nest or the incubating female by predators, we also indirectly considered the importance of olfaction by terrestrial mammals while searching for nests (Conover 2007; Conover et al. 2010; Dritz 2010). Similar to Moynahan et al. (2007), DSR of nests decreased the day after a rainfall event. Higher failure rates the day following precipitation events may have been caused by a combination of factors. First, female activity may have increased the day following precipitation as the result of reduced activity (i.e., greater attendance at the nest site) on the day of precipitation (Moynahan et al. 2007). Increased activity of the female on the day following precipitation could have drawn attention to the female or the nest by predators. Other possible explanations include (1) increased predator activity the day after precipitation events (Moynahan et al. 2007) due to reduced activity on the days of precipitation, and (2) high moisture contents in the air may have facilitated olfaction of predators (Gutzwiller 1990) that led them to the nest. For instance, a wet bird releases more scent than a dry bird because water molecules displace scent molecules on the skin and feathers and allow them to evaporate and enter the air column (Conover 2007). Therefore, it appears reasonable that moisture within the air can heighten the olfactory senses of predators because of increased scent released by the bird. 
A second weather variable (maximum wind speed), when added to the landscape model, improved model fit, providing further evidence of an olfactory cue used by predators to locate the source (i.e., the nest) of the scent. Wind speed influences olfaction of predators by carrying the scent over longer distances, allowing predators to track to the source of the scent (i.e., nest site). It has been hypothesized that high wind speeds will dilute odor plumes to undetectable levels or create odor plumes that are more difficult for a predator to follow (Conover 2007). However, in windy conditions, predators may require a consistent wind direction to navigate to the source of the odor (i.e., the nesting bird). It is interesting to note that the two weather variables most responsible for olfaction were included into the final models whereas temperature and humidity were not; a similar finding was observed by Dritz (2010).

There is a growing body of literature that points towards energy development as a factor in reduced demographic performance in certain species (e.g., Sawyer et al. 2009; Harju et al. 2010; Gilbert and Chalfoun 2011; Dzialak et al. 2011b) through means such as increased risk, landscape fragmentation, and altered predator communities and animal behavior. Typically, human-altered landscapes have a greater abundance of predators (Kurki et al. 1997, Kurki et al. 1998; Manzer and Hannon 2005), which is facilitated by infrastructure associated with wells that provide artificial perch sites for avian predators or ambush cover and den sites for terrestrial mammals (i.e., predator subsidization; Manzer and Hannon 2005; Coates and Delehanty 2010). Although predators will exploit human-altered landscapes, it may take several years for the full effects of disturbance to cascade across the landscape and influence predator occurrence. Therefore, it will be important to incorporate lag effects into model building to assess demographic responses related to disturbance that occurred in previous years. Harju et al. (2010) and Walker et al. (2007) report effects of previous development on population and breeding performance of sagegrouse. Therefore, we can infer that disturbance alters landscapes and subsequently influences predator search behavior or efficiency (Stephens et al. 2005).

In a recent study, the risk of losing a nest before hatch was most influenced by distance to mesic areas and wells; distance to roads did not structure nest survival (Dzialak et al. 2011a). We observed that DSR of nests was marginally greater for birds that nested closer to roads. However, the difference in distance to the nearest road between successful $(2,568 \mathrm{~m})$ and unsuccessful (2,693 m) birds was $125 \mathrm{~m}$, which could be considered biologically insignificant. Given that birds nested away from roads in general (mean $\geq 2,568 \mathrm{~m}$ ), the minimal difference in distance to the nearest road between the two groups $(125 \mathrm{~m})$ and the finding that roads did not structure the risk of nest failure (Dzialak et al. 2011a) provides further support of the importance of other factors in structuring DSR of nests in this ground-nesting bird of conservation concern.

Many species of grouse select for habitats with mesic areas nearby for various life-history phases (Walker et al. 2007). We found that nest survival was lowest when nests were within $50 \mathrm{~m}$ from mesic habitat. This relationship may be caused by the use of mesic habitat by predators (Stephens et al. 2005; Walker et al. 2007), many of which function as travel corridors, edge habitat, or ambush sites for terrestrial predators (Winter et al. 2000). While mesic areas associated with anthropogenic features of the landscape reduced nest survival (Dzialak et al. 2011a), DSR of nests was reduced when in proximity to any mesic area, likely due to the functional habitat value of the area for a wide number of avian and terrestrial predators. In other studies, taller vegetation associated with mesic areas increased the number of perch sites for avian predators, thus facilitating predation of nests by avian predators (Manzer and Hannon 2005). Although any type of mesic area reduced DSR of nests, careful attention should be paid to water discharge associated with anthropogenic activities (e.g., agriculture irrigation, oil and gas extraction, and ranching), which would artificially create and inflate the number of mesic areas (example of predator subsidization).

\section{Conclusions}

Nest site-specific landscape variables most influenced DSR of nests in this sagebrush-obligate species, the greater sage-grouse. However, managing for microsite landscape characteristics is difficult. Large-scale management practices are readily implemented across the landscape; thus, predictive mapping of the landscape factors responsible for nest survival (longer temporal scale than DSR) may be more appropriate for applying management actions (Dzialak et al. 2011a). This management action does not take away from the fact that microsite characteristics are important to DSR of nests. Nest sites are located in a broader landscape context, which supports earlier studies which found that predators selected landscape characteristics (including human-altered areas) at larger spatial extents (Chalfoun et al. 2002; Stephens et al. 2005). This may lead to reduced DSR of nests when nest sites are located within the larger landscape selected by predators or in landscapes where human activity subsidizes predators. Therefore, predators appear to be the proximate cause of reduced DSR of nests whereby predator senses, such as visual and olfactory acuities, are heightened in certain landscapes and under variable weather conditions. However, the ultimate cause of nest failure may stem from alterations 
to the landscape that typically occur across large spatial extents leading to subsidized predator communities or decoupled selection decisions used during nest site selection. Although weather patterns cannot be managed per se, managers can use predictive mapping of spatial attributes of the landscape and model seasonal nest survival by including weather patterns experienced over the nesting period to predict annual trends of breeding dynamics.

\section{Appendix}

\section{Appendix 1}

\section{Statistical code used to analyze DSR of nests}

Statistical analysis $\left(\mathrm{SAS}^{\circledR}\right.$ 9.2, SAS Institute Inc., Cary, NC, USA) code was used to analyze DSR of nests of female greater sage-grouse (C. urophasianus) in the Wind River Basin in central Wyoming, USA. The statistical procedure (i.e., GLIMMIX) used was a GLMM capable of modeling both fixed and random effects.

PROC GLIMMIX DATA = SG_DSR METHOD = LAPLACE;/"Specifies using the Laplace method of approximating the log likelihood*/

CLASS BIRD NID YEAR PRECIPLAG;/*Categorical variables for individual birds (BIRD), nest identification (NID), year (YEAR), and 1-day lag in precipitation $(0=$ no rain; 1 = rain $\geq 0.0254 \mathrm{~cm}$; PRECIPLAG)*/

MODEL STATUS $($ EVENT $=' 1$ ') = JULIAN NESTAGE SHRUBS WELLOLAG_LOG

DISTROAD DISTMESIC_LOG WINDMAXKPH WINDMAXKPH_QUAD

PRECIPLAG/SOLUTION DIST = BINOMIAL LINK $=$ LOGIT CL;/"Status refers to whether the nest survived (event $=1$ ) or failed (event $=0$ ) the 1 -day interval; in this case we are modeling probability of survival $($ event $=1) * /$

/"What follows next are the independent variables that can be either categorical or continuous, and either timeconstant (e.g., landscape variables such as percentage of shrub canopy cover [SHRUBS], natural log-transformed distance to oil and gas wells [WELLOLAG_LOG], distance to nearest road [DISTROAD], and natural logtransformed distance to nearest mesic habitat [DISTMESIC_LOG]) or time-specific (e.g., weather variables such as maximum wind speed [WINDMAXKPH] and a 1-day lag in precipitation [PRECIPLAG])*/

/"Nest status was modeled as following a binomial distribution with a logit link function; the "SOLUTION" option requests display of coefficient estimates and standard errors, and "CL" requests confidence limits on the coefficient estimates for each independent variable*/

/*The following random statements model the hierarchical structure of the data*/

RANDOM NID(BIRD) $/$ TYPE $=$ VC; $/ *$ Fates of nests within each nesting attempt are "nested" within each individual bird (i.e., nest fates may be correlated within individual birds); "TYPE $=$ VC" models the correlation among nests within birds using a variance components covariance structure (this is the default in SAS but other covariance structures can be specified). This means that variance components are modeled separately for each random effect and are independent." /

RANDOM BIRD $($ YEAR $) /$ TYPE $=$ VC; /"Fates of nests within birds are "nested" within each year (i.e., nest fates may be correlated within individual birds within each year). For birds sampled in multiple years, nest fate may be correlated within years for that bird but are assumed independent among years." /

RANDOM YEAR/TYPE = VC; $/$ "Fates of nests may be correlated within years. For example, due to weather, some years may have high nest failure rates for all birds. This accounts for that fact to better estimate the effect of other independent variables. ${ }^{*}$

\section{RUN;}

\section{Abbreviations}

AIC: Akaike's information criterion; AICc: Akaike's information criterion corrected for small sample size; DEM: digital elevation model; DSR: daily survival rate; GLMM: generalized linear mixed model; GPS: global positioning system; PTT: platform terminal transmitters; $w_{i}$ : Akaike weights.

\section{Acknowledgements}

Funding was provided by ConocoPhillips, EnCana Oil and Gas, and Noble Energy. We thank S. Oberlie (Bureau of Land Management) and G. Anderson (Wyoming Game and Fish Department) for the logistical support; the Lander Sage-Grouse Working Group for providing six transmitters; C. Aldridge (United States Geologic Survey) for providing remotely sensed sagebrush habitat quantification products for Wyoming; J. Mudd for the GIS support; M. Pollock for the early project input and data management; and J. Dinkins, C. Hedley, and several anonymous reviewers for improving the early versions of this manuscript. KC Harvey Environmental, LLC provided in-kind support to $\mathrm{DL}$ during the drafting and revising of this manuscript. The commercial funding sources were not involved with the design and development of the research protocol; collection, analysis, or interpretation of data; the writing of this manuscript; or the decision to submit this manuscript.

\section{Author details}

'Hayden-Wing Associates, LLC, 2308 South 8th Street, Laramie, WY, 82070, USA ${ }^{2}$ KC Harvey Environmental, LLC, 376 Gallatin Park Drive, Bozeman, MT, 59715, USA

\section{Authors' contributions}

SLW designed the study, managed and analyzed the data, wrote the statistical code, and drafted the manuscript. CVO designed the study, managed the data, and helped draft the manuscript. MRD designed the study, provided statistical assistance, analyzed portions of the data set, and helped draft the manuscript. SMH assisted in developing the statistical code and in drafting the manuscript. JBW designed the study and reviewed the manuscript drafts. DL designed the study, collected the field data, and reviewed the manuscript drafts. All authors read and approved the final manuscript.

\section{Competing interests}

This work was funded by commercial sources: ConocoPhillips, EnCana Oil and Gas, and Noble Energy. Hayden-Wing Associates, LLC provided in-kind contributions that included travel costs associated with the dissemination of this work and materials associated with data collection and analysis such as GPS devices and statistical analysis software. Having received funding from commercial sources, the consultancy could reasonably be perceived as a 
financial competing interest. This does not alter the authors' views or adherence to journal policies on publishing original scientific findings. Last, the commercial funding sources were not involved with the design and development of the research protocol; the collection, analysis, or interpretation of data; the writing of this manuscript; or the decision to submit this manuscript.

Received: 6 September 2011 Accepted: 10 February 2012 Published: 10 February 2012

\section{References}

Aldridge CL, Boyce M (2007) Linking occurrence and fitness to persistence: habitat based approach for endangered greater sage-grouse. Ecol Appl 17:508-526

Becker JM, Duberstein CA, Tagestad JD, Downs JL (2009) Sage-grouse and wind energy: biology, habits and potential effects from development, report number PNNL-18567. Pacific Northwest National Laboratory, Richland

Bedrosian B, Craighead D (2007) Evaluation of techniques for attaching transmitters to common raven nestlings. Northwest Nat 88:1-6

Burhans DE, Dearborn D, Thompson FR III, Faaborg J (2002) Factors affecting predation at songbird nests in old fields. J Wild Manage 66:240-249

Burnham KP, Anderson DR (2002) Model selection and inference: a practical information-theoretic approach. Springer, New York

Canfield RH (1941) Application of the line interception method in sampling range vegetation. J For 39:388-394

Cao J, He CZ, Wells KMS, Millspaugh JJ, Ryan MR (2009) Modeling age and nestspecific survival using a hierarchical Bayesian approach. Biom 65:1052-1062

Chalfoun AD, Martin TE (2009) Habitat structure mediates predation risk for sedentary prey: experimental tests of alternative hypotheses. J Anim Ecol 78:497-503

Chalfoun AD, Thompson FR III, Ratnaswamy MJ (2002) Nest predators and fragmentation: a review and meta-analysis. Conser Biol 16:306-318

Coates PS, Delehanty DJ (2010) Nest predation of greater sage-grouse in relation to microhabitat factors and predators. J Wildl Manage 74:240-248

Connelly JW, Braun CE (1997) Long-term changes in sage grouse Centrocercus urophasianus populations in western North America. Wildl Biol 3:229-234

Connelly JW, Wakkinen WL, Apa AD, Reese KP (1991) Sage grouse use of nest sites in southeastern Idaho. J Wildl Manage 55:521-524

Conover MR (2007) Predator-prey dynamics: the use of olfaction. Taylor and Francis, Boca Raton

Conover MR, Borgo JS (2009) Do sharp-tailed grouse select loafing sites to avoid visual or olfactory predators? J Wild Manage 73:242-247

Conover MR, Borgo JS, Dritz RE, Dinkins JB, Dahlgren DK (2010) Greater sagegrouse select nest sites to avoid visual predators but not olfactory predators. Condor 112:331-336

Conway CJ, Martin TE (2000) Evolution of passerine incubation behavior: influence of food, temperature, and nest predation. Evolution 54:670-685

Crawford JA, Olson RA, West NE, Mosley JC, Schroeder MA, Whitson TD, Miller RF, Gregg MA, Boyd CS (2004) Ecology and management of sagegrouse and sage-grouse habitat. J Range Manage 57:2-19

Crooks KR, Soulé ME (1999) Mesopredator release and avifaunal extinctions in a fragmented system. Nature 400:563-565

Crunden CW (1963) Age and sex of sage-grouse from wings. J Wildl Manage 27:846-849

Daubenmire RF (1959) A canopy-coverage method of vegetation analysis. Northwest Sci 33:43-64

Dinsmore SJ, White GC, Knopf FL (2002) Advanced techniques for modeling avian nest survival. Ecology 83:3476-3488

Doherty KE, Naugle DE, Walker BL, Graham JM (2008) Greater sage-grouse winter habitat selection and energy development. J Wild Manage 72:187-195

Dritz RE (2010) Influence of landscape and weather on foraging by olfactory meso-predators in Utah. Thesis, Utah State University

Dzialak MR, Olson CV, Harju SM, Webb SL, Mudd JP, Winstead JB, HaydenWing LD (2011) Identifying and prioritizing greater sage-grouse nesting and brood-rearing habitat for conservation in human-modified landscapes. PLoS ONE 6(10):e26273. doi:10.1371/journal.pone.0026273

Dzialak MR, Webb SL, Harju SM, Winstead JB, Wondzell JJ, Mudd JP, HaydenWing LD (2011) The spatial pattern of demographic performance as a component of sustainable landscape management and planning. Landsc Ecol 26:775-790
Eng RL (1955) A method for obtaining sage grouse age and sex ratios from wings. J Wildl Manage 19:267-272

Gilbert MM, Chalfoun AD (2011) Energy development affects populations of sagebrush songbirds in Wyoming. J Wildl Manage 75:816-824

Grant TA, Shaffer TL, Madden EM, Pietz PJ (2005) Time-specific variation in passerine nest survival: new insights into old questions. Auk 122:661-672

Gregg MA, Crawford JA, Drut MS, DeLong AK (1994) Vegetational cover and predation of sage grouse nests in Oregon. J Wildl Manage 58:162-166

Gutzwiller KJ (1990) Minimizing dog-induced biases in game bird research. Wildl Soc Bull 18:351-356

Harju SM, Dzialak MR, Taylor RC, Hayden-Wing LD, Winstead JB (2010) Thresholds and time lags in the effects of energy development on greater sage-grouse populations. J Wildl Manage 74:437-448

Holloran MJ, Anderson SH (2005) Spatial distribution of greater sage-grouse nests in relatively contiguous sagebrush habitats. Condor 107:742-752

Holloran MJ, Heath BJ, Lyon AG, Slater SJ, Kuipers JL, Anderson SH (2005) Greater sage-grouse nesting habitat selection and success in Wyoming. J Wild Manage 69:638-649

Homer CG, Aldridge CL, Meyer DK, Schell S (2010) Provisional remote sensing sagebrush habitat quantification products for Wyoming. U.S. Geological Survey, Sioux Falls

Johnson CJ, Seip DR, Boyce MS (2004) A quantitative approach to conservation planning: using resource selection functions to map the distribution of mountain caribou at multiple spatial scales. J Appl Ecol 41:238-251

Klett AT, Johnson DH (1982) Variability in nest survival rates and implications to nesting studies. Auk 99:77-87

Kurki S, Helle P, Lindén H, Nikula A (1997) Breeding success of black grouse and capercaillie in relation to mammalian predator densities on two spatial scales. Oikos 79:301-310

Kurki S, Nikula A, Helle P, Lindén H (1998) Abundances of red fox and pine martin in relation to the composition of boreal forest landscapes. J Anim Ecol 67:874-886

Larivière S, Walton LR, Messier F (1999) Selection by striped skunks (Mephitis mephitis) of farmsteads and buildings as denning sites. Am Midl Nat 142:96-101

Lima SL (2009) Predators and the breeding bird: behavioral and reproductive flexibility under the risk of predation. Biol Rev 84:485-513

Lyon AG, Anderson SH (2003) Potential gas development impacts on sage grouse nest initiation and movement. Wildl Soc Bull 31:486-491

Manzer DL, Hannon SJ (2005) Relating grouse nest success and corvid density to habitat: a multi-scale approach. J Wildl Manage 69:110-123

Moynahan BJ, Lindberg MS, Rotella JJ, Thomas JW (2007) Factors affecting nest survival of greater sage-grouse in northcentral Montana. J Wildl Manage 71:1173-1783

Nams VO (1997) Density-dependent predation by skunks using olfactory search images. Oecologia 110:440-448

Sargeant AB, Sovada MA, Greenwood RJ (1998) Interpreting evidence of depradation of duck nests in the prairie pothole region. U.S. Geological Survey Northern Prairie Wildlife Research Center, Jamestown

Sawyer H, Kauffman MJ, Nielson RM (2009) Influence of well pad activity on winter habitat selection patterns of mule deer. J Wild Manage 73:1052-1061

Schroeder MA, Young JR, Braun CE (1999) Greater sage-grouse (Centrocercus urophasianus). In: Poole A (ed) The Birds of North America, No. 425. Cornell Lab of Ornithology, Ithaca

Schroeder MA, Aldridge CL, Apa AD, Bohne JR, Braun CE, Bunnell SW, Connelly JW, Deibert PA, Gardner SC, Hilliard MA, Kobriger GD, McAdam SM, McCarthy CW, McCarthy JJ, Mitchell DL, Rickerson EV, Stiver SJ (2004) Distribution of sagegrouse in North America. Condor 106:363-376

Shaffer TL (2004) A unified approach to analyzing nest success. Auk 121:526-540

Stephens SE, Koons DN, Rotella JJ, Willey DW (2003) Effects of habitat fragmentation on avian nesting success: a review of the evidence at multiple spatial scales. Biol Conser 115:101-110

Stephens SE, Rotella JJ, Lindberg MS, Taper ML, Ringelman JK (2005) Duck nest survival in the Missouri Coteau of North Dakota: landscape effects at multiple spatial scales. Ecol Appl 15:2137-2149

Storaas T (1988) A comparison of losses in artificial and naturally occurring capercaillie nests. J Wildl Manage 52:123-126

United States Fish and Wildlife Service (2010) Endangered and threatened wildlife and plants: 12-month finding for petitions to list the greater sagegrouse (Centrocercus urophasianus) as threatened or endangered. Fed Reg 75:13910-14014 
Visual Learning Systems, Inc (2008) Feature Analyst 4.2 for ArcGIS ${ }^{\bullet}$ reference manual. Visual Learning Systems, Inc., Missoula

Wakkinen WL, Reese KP, Connelly JW, Fischer RA (1992) An improved spotlighting technique for capturing sage-grouse. Wildl Soc Bull 20:425-426

Walker BL, Naugle DE, Doherty KE (2007) Greater sage-grouse population response to energy development and habitat loss. J Wildl Manage 71:2644-2654

Webb SL, Dzialak MR, Wondzell JJ, Harju SM, Hayden-Wing LD, Winstead JB (2011) Survival and cause-specific mortality of female Rocky Mountain elk exposed to human activity. Popul Ecol 53:483-493

Wiens JA (1989) Spatial scaling in ecology. Funct Ecol 3:385-397

Winter M, Johnson DH, Faaborg J (2000) Evidence for edge effects on multiple levels in tallgrass prairie. Condor 102:256-266

doi:10.1186/2192-1709-1-4

Cite this article as: Webb et al:: Landscape features and weather influence nest survival of a ground-nesting bird of conservation concern, the greater sage-grouse, in human-altered environments. Ecological Processes 2012 1:4.

\section{Submit your manuscript to a SpringerOpen ${ }^{\odot}$ journal and benefit from:}

- Convenient online submission

- Rigorous peer review

- Immediate publication on acceptance

- Open access: articles freely available online

- High visibility within the field

- Retaining the copyright to your article

Submit your next manuscript at $>$ springeropen.com 